\title{
Lentiviral CRISPR/Cas9 nickase vector mediated BIRC5 editing inhibits epithelial to mesenchymal transition in ovarian cancer cells
}

\author{
Guannan Zhao ${ }^{1,2, *}$, Qinghui Wang ${ }^{3, *}$, Qingqing Gu ${ }^{1,2}$, Wenan Qiang ${ }^{4,5}$, Jian-Jun Wei ${ }^{4}$, \\ Peixin Dong ${ }^{6,7}$, Hidemichi Watari ${ }^{6,7}$, Wei $\mathbf{L i}^{3}$ and Junming Yue ${ }^{1,2}$ \\ ${ }^{1}$ Department of Pathology and Laboratory Medicine, University of Tennessee Health Science Center, Memphis, USA \\ ${ }^{2}$ Center for Cancer Research, University of Tennessee Health Science Center, Memphis, USA \\ ${ }^{3}$ Department of Pharmaceutical Sciences, University of Tennessee Health Science Center, Memphis, USA \\ ${ }^{4}$ Department of Pathology, Department of Obstetrics and Gynecology, Northwestern University School of Medicine, Chicago, \\ USA \\ ${ }^{5}$ Center for Developmental Therapeutics, Chemistry of Life Processes Institute, Northwestern University, Evanston, \\ USA \\ ${ }^{6}$ Department of Women's Health Educational System, Hokkaido University School of Medicine, Hokkaido University, Sapporo, \\ Japan \\ ${ }^{7}$ Department of Gynecology, Hokkaido University School of Medicine, Hokkaido University, Sapporo, Japan \\ *These authors have contributed equally to this work \\ Correspondence to: Junming Yue, email: jyue@uthsc.edu \\ Wei Li, email: wli@uthsc.edu \\ Keywords: BIRC5 (survivin), CRISPR/Cas9 nickase, lentiviral vector, ovarian cancer, epithelial to mesenchymal transition \\ Received: March 29, $2017 \quad$ Accepted: September 18, $2017 \quad$ Published: October 17, 2017 \\ Copyright: Zhao et al. This is an open-access article distributed under the terms of the Creative Commons Attribution License 3.0 \\ (CC BY 3.0), which permits unrestricted use, distribution, and reproduction in any medium, provided the original author and source \\ are credited.
}

\section{ABSTRACT}

BIRC5 encodes the protein survivin, a member of the inhibitor of apoptosis family. Survivin is highly expressed in a variety of cancers but has very low expression in the corresponding normal tissues, and its expression is often associated with tumor metastasis and chemoresistance. We report that survivin was highly expressed in ovarian cancer and strongly correlated with patient overall poor survival. For the first time, we provide experimental evidence that survivin is involved in epithelial to mesenchymal transition (EMT) in ovarian cancer cells. Lentiviral CRISPR/Cas9 nickase vector mediated BIRC5 gene editing led to the inhibition of EMT by upregulating epithelial cell marker, cytokeratin 7 and downregulating mesenchymal markers: snail2, $\beta$-catenin, and vimentin in both ovarian cancer SKOV3 and OVCAR3 cells. Consistent with this molecular approach, pharmacological treatment of ovarian cancer cells using a small molecule survivin inhibitor, YM155 also inhibited EMT in these ovarian cancer cell lines. Overexpression of BIRC5 promoted EMT in SKOV3 cells. Using molecular or pharmacological approaches, we found that cell proliferation, migration, and invasion were significantly inhibited following BIRC5 disruption in both cell lines. Inhibition of BIRC5 expression also sensitized cell responses to paclitaxel treatment. Moreover, loss of BIRC5 expression attenuated TGF $\beta$ signaling in both SKOV3 and OVCAR3 cells. Collectively, our studies demonstrated that disruption of BIRC5 expression inhibited EMT by attenuating the TGF $\beta$ pathway in ovarian cancer cells. 


\section{INTRODUCTION}

Ovarian cancer is therapeutically challenging and has the highest mortality rate among gynecological malignancies. It has been estimated that there will be 22,440 new ovarian cancer cases and 14,080 deaths in 2017 in the United States [1]. Ovarian cancer is rarely detected early, and the majority of patients are already at advanced stages at the time of diagnosis. Moreover, ovarian cancers primarily metastasize through peritoneal dissemination from the primary tumor site to other distant organs including the omentum, colon, and liver. This metastatic process is often accompanied by ascitic fluid accumulation, which is associated with tumor metastasis and chemoresistance, further contributing to a poor survival rate in patients $[2,3]$. The current clinical therapy is to perform debulking surgery followed by chemotherapy [4]. However, ovarian cancers are frequently recurrent, and become chemoresistant once recurrence occurs. The current therapeutic approaches are limited due to a lack of understanding the molecular mechanisms underlying tumor metastasis and chemoresistance.

Epithelial to mesenchymal transition (EMT) is a biological process whereby epithelial cells acquire mesenchymal phenotypes by losing their polarity and cellcell adhesion and gain migratory or invasive properties [5]. During the EMT process, epithelial markers such as E-cadherin, are downregulated, and mesenchymal markers such as snai2, vimentin, and $\beta$-catenin are upregulated [6]. The EMT process is regulated by multiple signaling pathways, including TGF $\beta$, WNT, HMGA2 and NFkB [6-9]. Extensive studies have indicated that EMT contributes to tumor metastasis and chemoresistance [10-12]. In ovarian cancers, EMT is also associated with peritoneal metastasis and chemotherapy drug resistance and with a poor survival rate in patients $[6,12-15]$.

BIRC5 (baculoviral IAP repeat containing 5) encodes survivin as the smallest member of the inhibitors of apoptosis family. Survivin is highly expressed in various human cancers, including ovarian cancer, and its expression is very low in fully differentiated normal adult tissues [16]. Survivin expression is associated with tumor metastasis and chemoresistance in a number of cancer types such as melanoma, renal, prostate, and breast [1720]. In ovarian cancer, survivin has also been shown to contribute to tumor metastasis and chemoresistance [12, 21-24]. However, the molecular mechanism underlying survivin-associated tumor metastasis and chemoresistance is still not well understood.

In this study, we analyzed survivin expression in ovarian cancer patient samples and report that survivin was highly expressed in ovarian cancer and associated with poor survival. Lentiviral CRISPR/Cas9 nickase vector mediated BIRC5 editing led to the inhibition of EMT in ovarian cancer SKOV3 and OVCAR3 cells. Inhibition of BIRC5 expression by using a small molecule inhibitor of survivin, YM155, also suppressed EMT in both ovarian cancer cell lines. By using molecular or pharmacological approaches, intervening BIRC5 expression led to an inhibition of cell proliferation, migration, and invasion and sensitized cell response to chemotherapy drug treatment. In addition, inhibition of BIRC5 expression attenuated the TGF $\beta$ pathway in both SKOV3 and OVCAR3 cells. Our results indicated that survivin may contribute to tumor metastasis and chemoresistance by promoting EMT through the TGF $\beta$ pathway in ovarian cancer cells.

\section{RESULTS}

\section{BIRC5 was highly expressed in ovarian cancer and associated with poor survival in patients}

To examine the expression level of BIRC5 in ovarian cancer, we analyzed TCGA datasets that included 586 serous ovarian carcinomas and 8 normal ovary controls [25]. BIRC5 expression was significantly higher by approximately a 5 -fold increase in tumors than in controls $(P=2.20 \mathrm{E}-10)$ (Figure 1A). We also analyzed 185 ovarian carcinomas and 10 normal ovarian surface epithelia in the Oncomine database [26], and BIRC5 expression was significantly higher in tumors than in controls with approximately a 4-fold increase (Figure 1B). In addition, we examined BIRC5 expression in ovarian cancer in the Oncomine database including 43 serous carcinomas and 10 peritoneal controls [27]; BIRC5 expression showed approximately a 20 -fold increase in tumors compared to controls ( $P=5.68 \mathrm{E}-8)$ (Figure 1C). To confirm the findings of BIRC5 expression in ovarian cancer, we performed immunofluorescent staining on tumor sections of high grade serous ovarian carcinoma (Figure 1D) and found strong immunoreactivity for survivin in tumor cell nuclei but absent in the adjacent normal tissues (Figure 1E). We also examined survivin expression by immunohistochemistry and results indicated that survivin expression was significantly higher in HGSOC than in fallopian tubes (Figure 1F). In data set with information of clinical outcome (Gene Expression Omnibus (GSE13876) from 414 ovarian cancer patients), 207 patients were classified into the high expression group and the other 207 were classified into the low expression group by the median. Based on PROGgene program analysis [28], patients with high expression of survivin was significantly associated with poor survival and prognosis $(P=0.008$, Figure $1 \mathrm{G})$. All these data suggest that BIRC5 is highly expressed in high grade serous ovarian cancer and the level of survivin overexpression is associated with poor prognosis.

\section{Disruption of BIRC5 expression using lentiviral CRISPR/Cas9 nickase mediated editing resulted in the inhibition of EMT in ovarian cancer cells}

To disrupt BIRC5 expression in ovarian cancer cells, we examined endogenous BIRC5 expression in several ovarian cancer cell lines including SKOV3, OVCAR3, 
Hey and UACC1598 by western blot. Survivin was detected in all of them, and higher BIRC5 expression was found in SKOV3 and UACC1598 than Hey and OVCAR3 (Supplementary Figure 1A). SKOV3 and OVCAR3 cell lines were selected for our studies [29]. We constructed lentiviral CRISPR/Cas9 nickase by using two gRNAs targeting a region of exon 1 (Figure 2A) and then transduced both SKOV3 and OVCAR3 cells. The lentiviral CRISPR/Cas9 nickase vector-mediated mutations in SKOV3 cells were confirmed by using a DNA surveyor assay that the cleaved products were visible in cells transduced with BIRC5 gRNA vector but not in the control vector, indicating that BIRC5 mutation in exon 1 was successfully introduced by this approach (Figure 2B). Next, using Western blot, we examined whether the disruption of the BIRC5 gene resulted in alteration of the survivin protein and EMT-associated markers in both ovarian cancer cells. Survivin was remarkably depleted in both SKOV3 and OVCAR3 cells transduced with lentiviral BIRC5 gRNA vector (knockout) compared to control cells, and EMT markers were also altered by an upregulation of epithelial cell marker, cytokeratin-7 and downregulation of mesenchymal marker: vimentin, snai 2 and $\beta$-catenin compared to control cells (Figure 2C). To examine the
EMT phenotype in ovarian cancer cells, we treated SKOV3 cells using $10 \mathrm{ng} / \mathrm{ml}$ of TGF $\beta$ for $48 \mathrm{~h}$ and cell morphology was imaged. These images clearly showed a fibroblastlike mesenchymal morphology in TGF $\beta$ induced control cells, but not in the survivin knockout cells, indicating that loss of survivin inhibited TGF $\beta$ induced EMT in SKOV3 cells (Supplementary Figure 1B). We further examined EMT marker gene expression by treating both SKOV3 and OVCAR3 cells with different doses of YM155, a small molecule inhibitor of survivin. Following dosedependent inhibition of survivin, the epithelial cell marker, cytokeratin-7 was upregulated and mesenchymal markers: vimentin, snai2, and $\beta$-catenin were downregulated in both SKOV3 and OVCAR3 cells (Figure 2D, 2E). Disruption of BIRC5 with CRISPR/Cas9 nickase or inhibition of BIRC5 with a small inhibitor resulted in the inhibition of EMT in both SKOV3 and OVCAR3 cells. After BIRC5 was overexpressed using lentiviral overexpression vector in SKOV3 cells, survivin and EMT markers were examined by Western blot. We observed an upregulation of vimentin, snail2 and $\beta$-catenin and a downregulation of cytokeratin-7 following BIRC5 overexpression, indicating that survivin expression promoted EMT in ovarian cancer SKOV3 cells (Figure 2F).
A

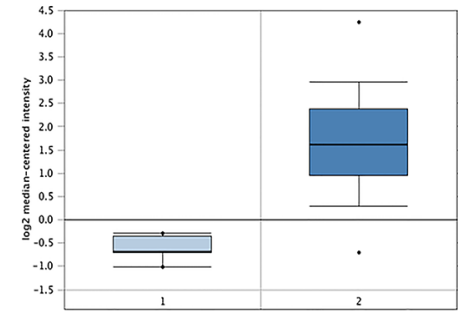

B

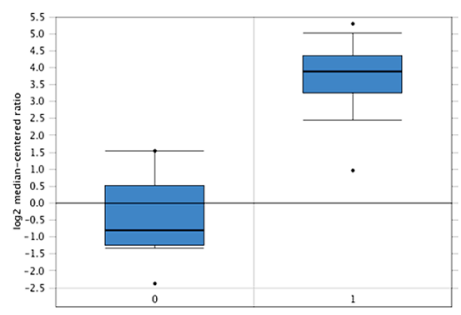

C

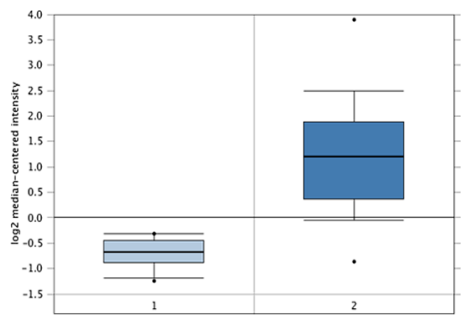

D

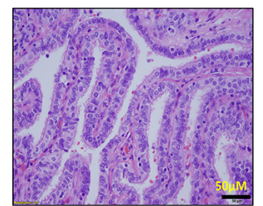

E
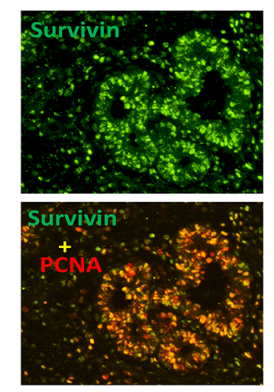

F

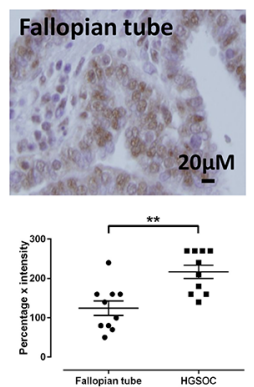

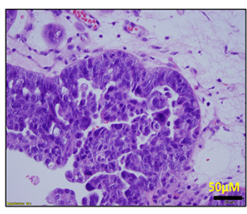
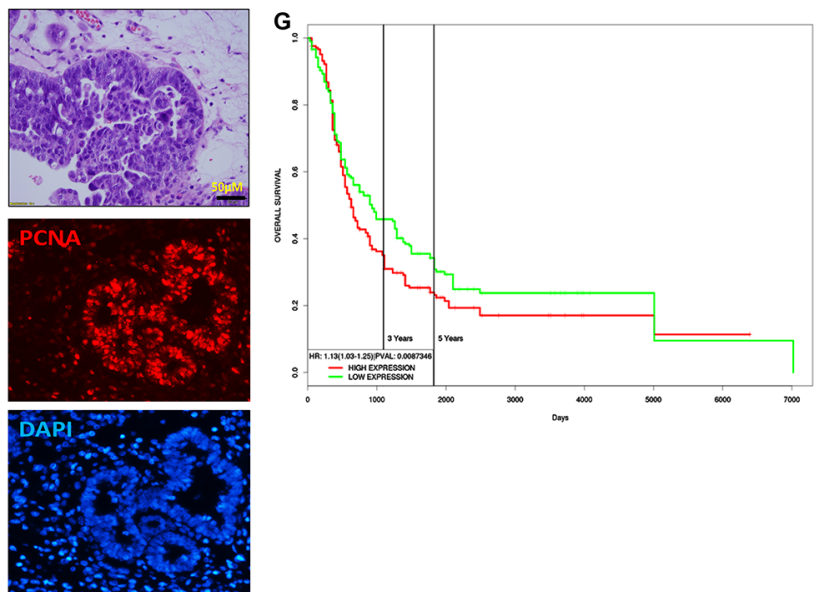

Figure 1: BIRC5 was highly expressed in ovarian serous carcinoma and associated with poor patient survival. (A) $1=$ Normal ovary tissue $(\mathrm{N}=8) ; 2=$ Ovarian cancer $(\mathrm{N}=586)$. (B) 1 = Normal ovarian surface epithelium $(\mathrm{N}=10) ; 2=$ Ovarian cancer $(\mathrm{N}=185)$. (C) 1 = Normal peritoneum tissue $(\mathrm{N}=10)$; $2=$ Ovarian cancer $(\mathrm{N}=43)$. (D) H.E. staining of ovarian serous carcinoma in low and high magnification. (E) Immunofluorescent staining of survivin and PCNA in sections of ovarian serous carcinoma. (F) Immunohistochemical staining of survivin in normal fallopian tubes and high grade serous ovarian carcinoma $\left(\mathrm{n}=10,{ }^{* *} \mathrm{p}<0.01\right)$. (G) BIRC5 expression and ovarian patient survival in ovarian serous carcinoma $(n=207, p=0.0008)$. 


\section{Disruption of BIRC5 expression led to the inhibition of cell proliferation and survival in ovarian cancer cells}

To determine the functional outcome of losing BIRC5 expression in ovarian cancer cells, we examined cell proliferation in SKOV3 and OVCAR3 cells with and without BIRC5 expression. Disruption of BIRC5 by CRISPR/Cas9 nickase significantly reduced cell proliferation compared to controls at all three time points $(24,48$, and 72 h) in both SKOV3 and OVCAR3 cells (Figure 3A, 3B). We examined cell survival by assaying cell colony formation; loss of BIRC5 expression led to significant inhibition in both SKOV3 (Figure 3C) and OVCAR3 cells (Figure 3D). In addition, we tested the effect of two different doses of YM155 (0, 10 and $20 \mathrm{nM})$ on cell proliferation by treating wild type cells for 24,48 , and $72 \mathrm{~h}$, and cell proliferation was significantly inhibited in both SKOV3 (Figure 4A) and OVCAR3 (Figure 4B) cells. To examine how YM155 affected cell survival, we treated both SKOV3 and OVCAR3 cells using $5 \mathrm{nM}$ of YM155 and found that it significantly inhibited cell survival based on the colony formation assay (Figure 4C, 4D).

\section{Disruption of BIRC5 expression led to the inhibition of cell migration and invasion in ovarian cancer cells}

The loss of BIRC5 expression inhibited EMT in ovarian cancer cells and suggested that BIRC5 may affect cell motility and invasion. Using transwell plates, we examined cell migration in BIRC5 knockout and control cells and found that cell migration was significantly reduced in both the BIRC5 knockout, SKOV3 and OVCAR3 cells (Figure 5A). Using Matrigel-coated transwells, we assessed cell invasion, which was also significantly reduced in both SKOV3 and OVCAR3 cells compared to the controls (Figure 5B). To test whether survivin inhibitor has a similar effect on cell migration and invasion, we treated both cell lines with $20 \mathrm{nM}$ YM155 for $4 \mathrm{~h}$, and cell migration and invasion were determined with the same methods. Our results showed that inhibition of survivin with YM155 significantly reduced migration and invasion in both cell lines (Figure 6A, 6B).

\section{Disruption of BIRC5 expression sensitized cell responses to chemotherapy drug treatment}

BIRC5 expression in ovarian cancer cells may contribute to chemoresistance. To test whether a loss of BIRC5 expression sensitized the cell response to chemotherapy, we treated BIRC5 knockout and control SKOV3 and OVCAR3 cells with different doses of paclitaxel. Loss of BIRC5 expression induced cell apoptosis as shown by caspase $3 / 7$ activity and sensitized cell response to paclitaxel treatment at 20 and $40 \mathrm{nM}$ doses in both SKOV3 (Figure 7A) and OVCAR3 (Figure 7B) cells. Using Western blot, we also detected cell apoptosis by examining cleaved PARP and cleaved caspase3. Both apoptotic proteins were significantly induced by losing
A

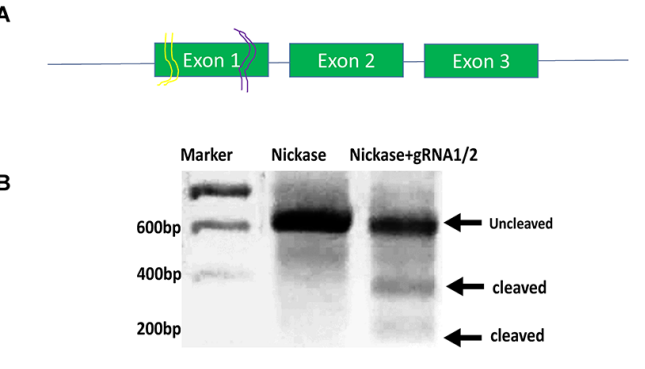

C
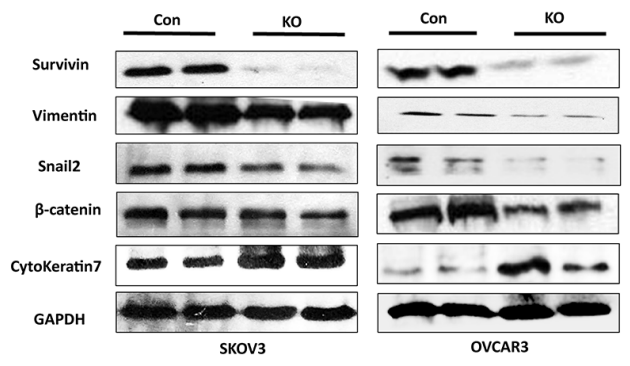
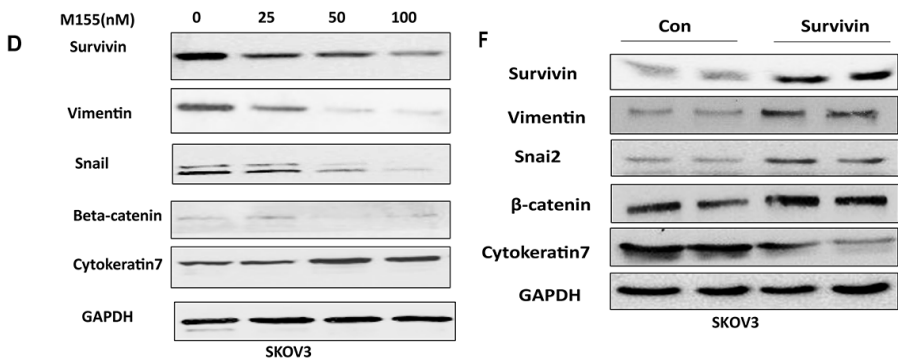

E

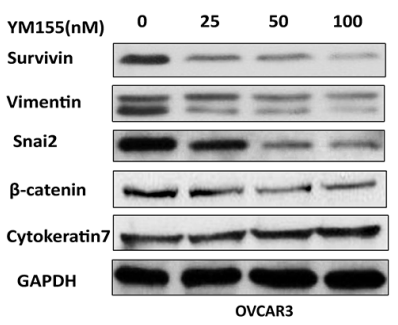

Figure 2: Lentiviral CRISPR/Cas9 nickase-mediated BIRC5 gene editing led to inhibition of EMT in ovarian cancer cells. (A) Schematic diagram of two gRNAs targeting exon 1 of BIRC5 gene. (B) DNA surveyor mutation assay showing two cleaved products presented in BIRC5 knockout, but not in control, cells. (C) EMT marker gene expression was examined in BIRC5 knockout and control SKOV3 and OVCAR3 cells by using Western blot. (D, E) EMT markers were examined in YM155-treated and control SKOV3 and OVCAR3 cells by Western blot. (F) EMT markers were examined by Western blot in BIRC5 expressing and control SKOV3 cells. 
BIRC5 expression with or without paclitaxel (Figure 7C). To test whether an inhibition of BIRC5 expression with YM155 also induced cell apoptosis, both SKOV3 and OVCAR3 cells were treated with different doses from 50 to $200 \mathrm{nM}$; using Western blot, we detected apoptosis by

A

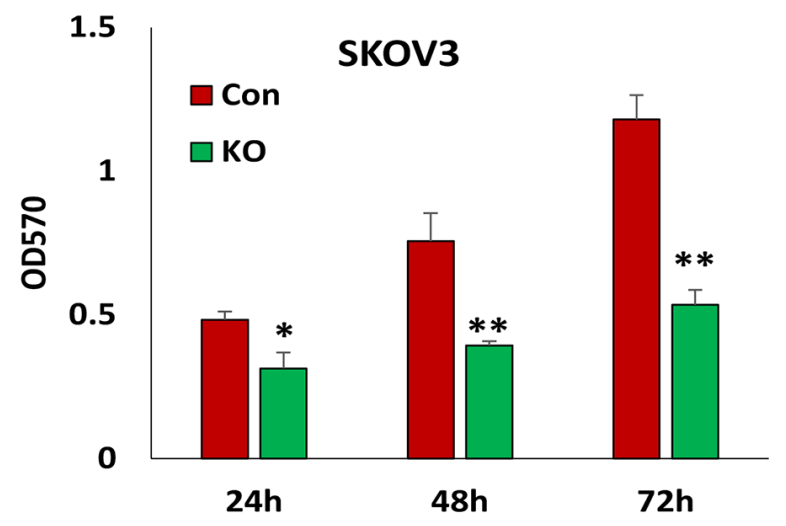

C

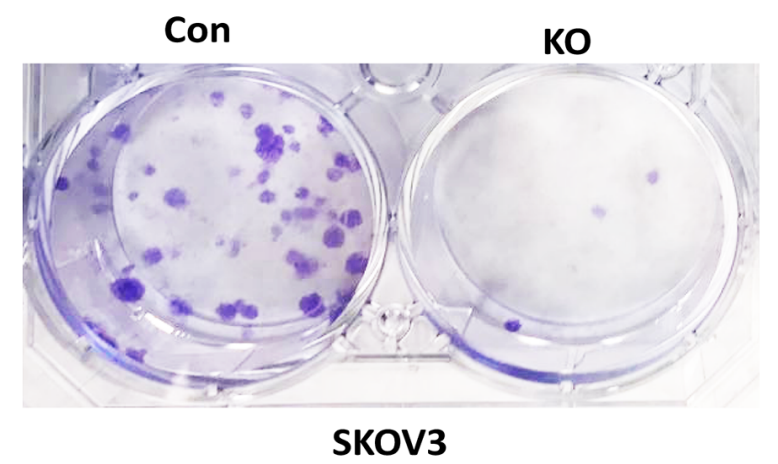

D

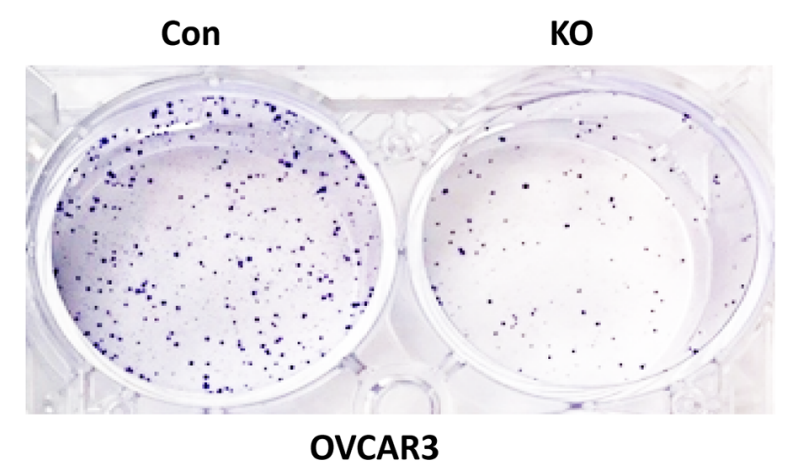

examining cleaved PARP and caspase 3 and found that inhibiting BIRC5 expression using YM155 induced cell apoptosis in both ovarian cancer cells (Figure 7D). Our data indicate that disruption of BIRC5 expression enhanced the efficacy of chemotherapy in ovarian cancer cells.

B
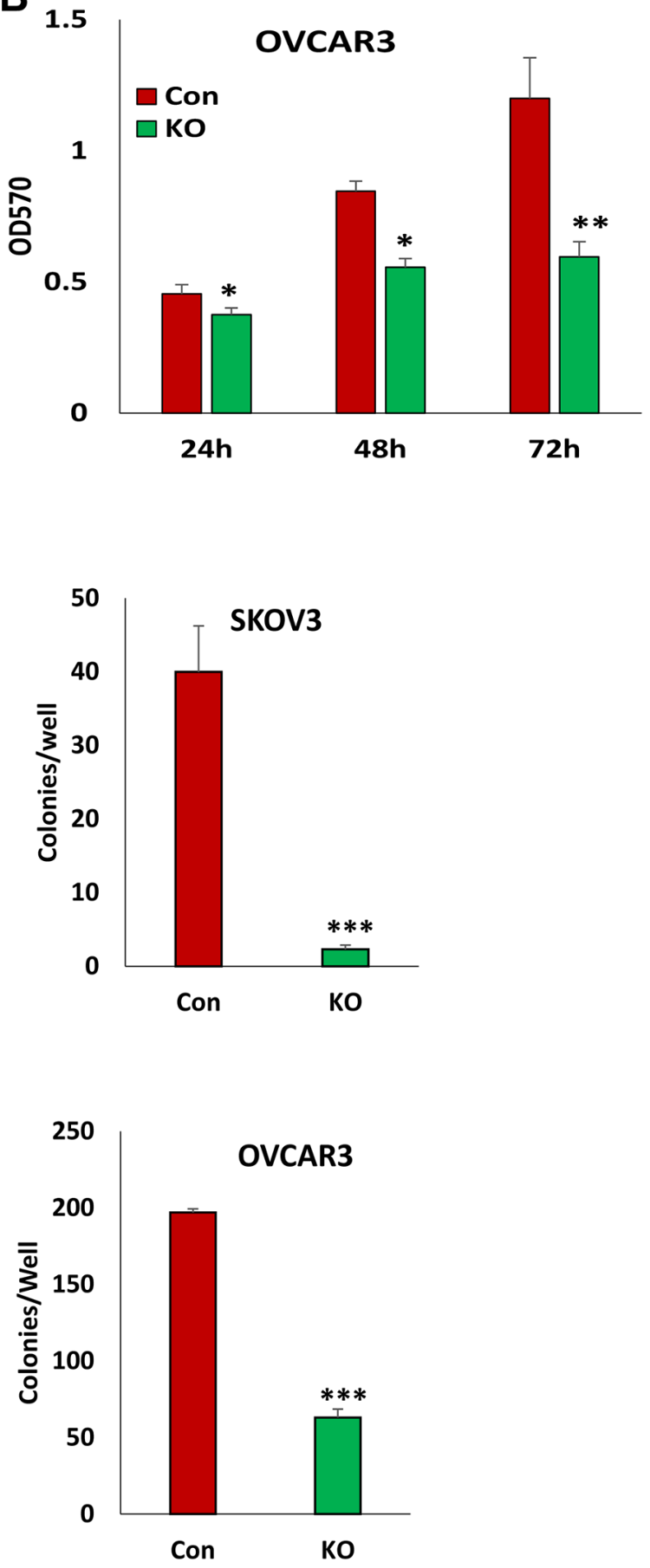

Figure 3: Lentiviral CRISPR/Cas9 nickase-mediated BIRC5 gene editing reduced cell proliferation in ovarian cancer cells. (A, B) Cell proliferation in BIRC5 knockout and control SKOV3(A) and OVCAR3 (B) cells at different time points was determined by MTT assay $\left({ }^{*} P<0.05 ;{ }^{* *} P<0.01\right)$. (C, D) Cell survival in BIRC5 knockout SKOV3 (C) and OVCAR3 (D) cells was determined by colony formation assay $\left({ }^{* * *} P<0.001\right)$. 


\section{Loss of BIRC5 expression attenuated TGF $\beta$ signaling pathway in ovarian cancer cells}

As we showed in our previous study, TGF $\beta$ promoted EMT in ovarian cancer cells [30]. To understand how BIRC5 regulates EMT in ovarian cancer cells, we tested the correlation between survivin and the TGF $\beta$ pathway in ovarian cancer cells. First, we determined

A

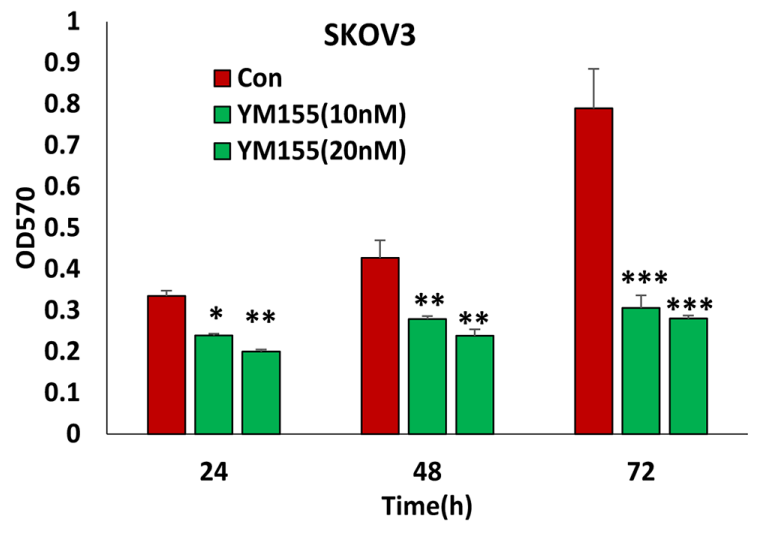

C

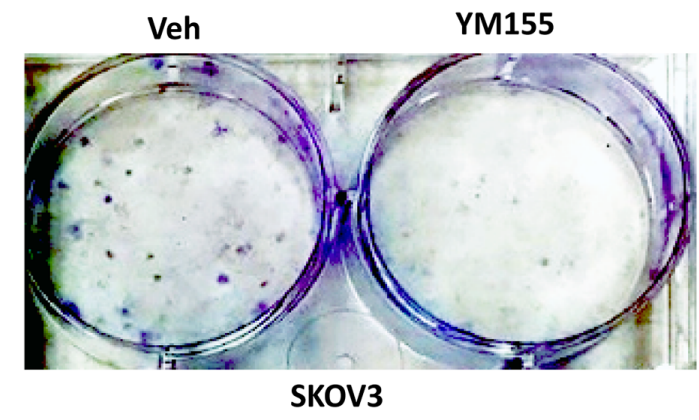

D

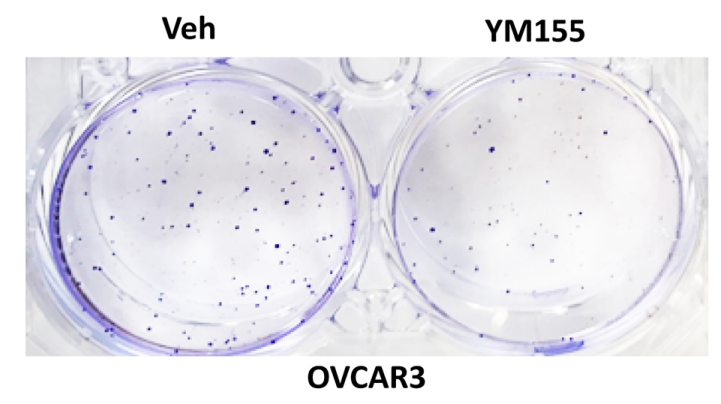

BIRC5 expression in both SKOV3 and OVCAR3 cells following TGF $\beta$ treatment at different time points $(0,6$, $12,24 \mathrm{~h})$ and found that TGF $\beta$ induced survivin expression (Figure 8A). Next, to determine whether BIRC5 expression was involved in the TGF $\beta$ pathway we treated BIRC5 knockout and control SKOV3 and OVCAR3 cells at different time points $(0,10$ and $20 \mathrm{~min})$ and then examined phospho- and total SMAD2 by using Western

B
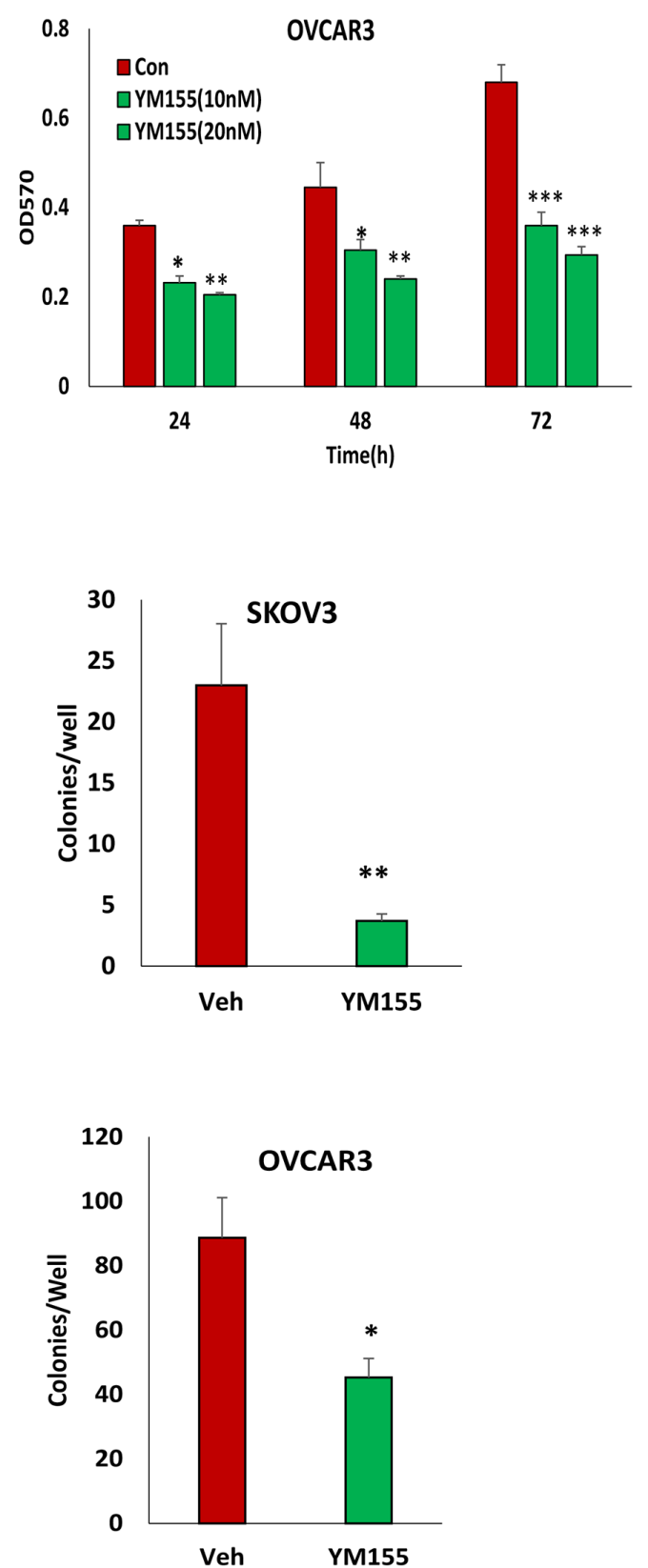

Figure 4: Inhibition of BIRC5 expression using YM155 reduced cell proliferation in ovarian cancer cells. (A, B) Cell proliferation in wild type ovarian cancer SKOV3 (A) and OVCAR3 (B) cells was determined following treatment using 10 and $20 \mathrm{nM}$ YM155 at different time points by MTT assay $\left({ }^{*} P<0.05 ;{ }^{* *} P<0.01 ;{ }^{* * *} P<0.001\right)$. (C, D) Cell survival was determined using a colony formation assay following treatment with $5 \mathrm{nM}$ YM1 $55\left({ }^{*} P<0.05 ;{ }^{* *} P<0.01 ;{ }^{* * *} P<0.001\right)$. 
A
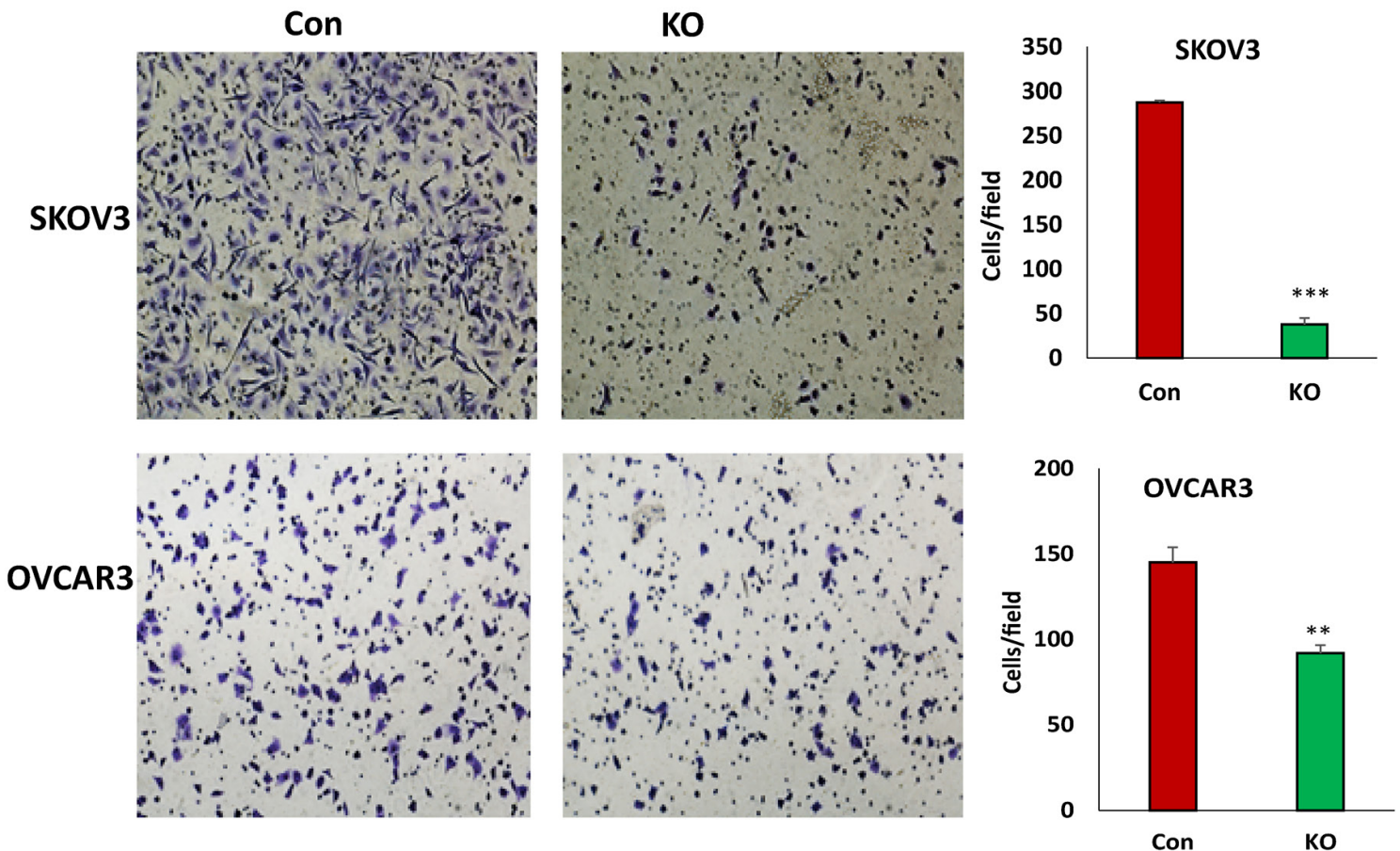

B
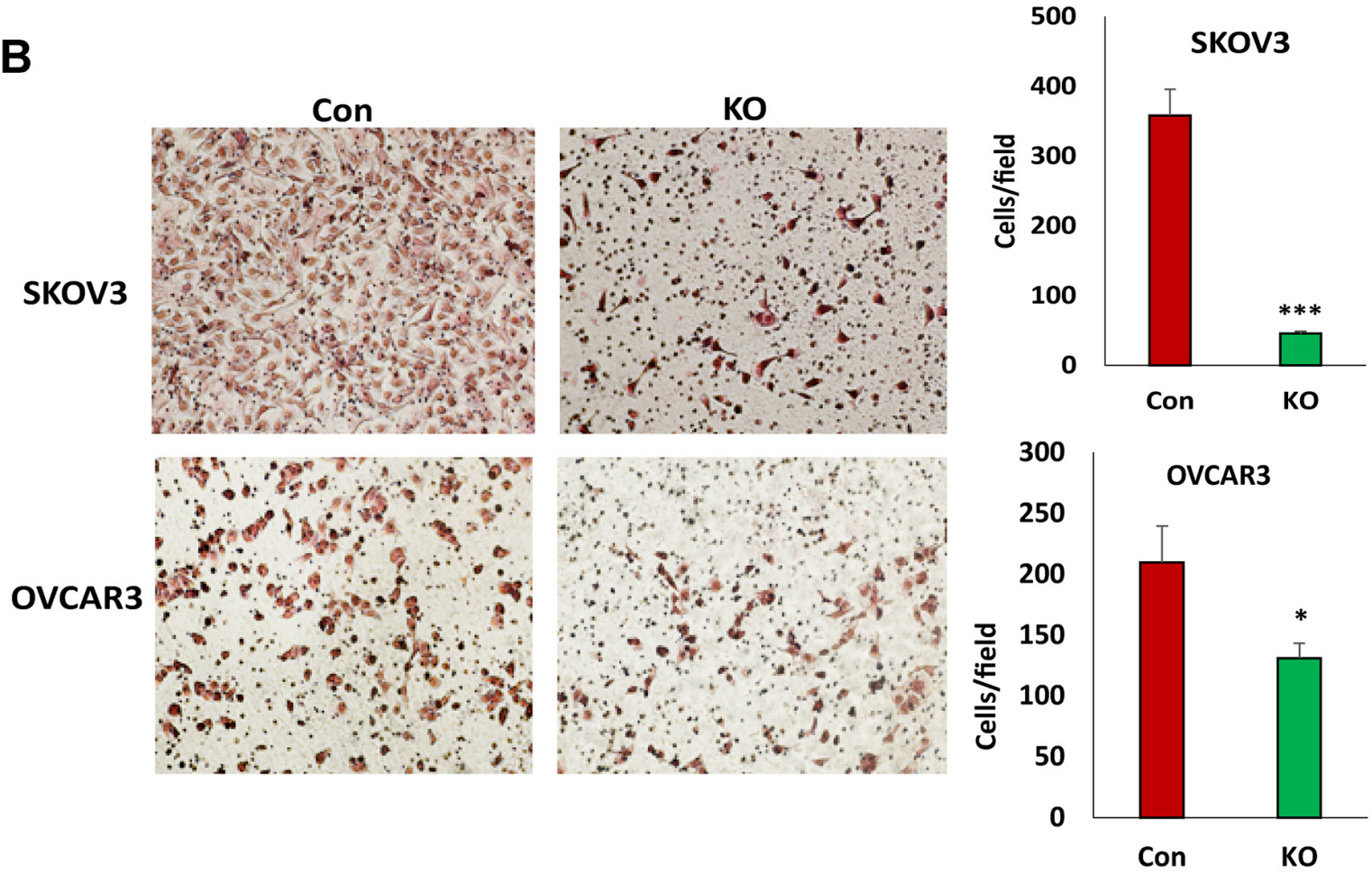

Figure 5: Lentiviral CRISPR/Cas9 nickase mediated BIRC5 gene editing reduced cell migration and invasion in ovarian cancer cells. (A) Cell migration in BIRC5 knockout and control SKOV3 or OVCAR3 cells was examined using transwell plates, and migrated cells were stained with crystal blue and counted $\left({ }^{* *} P<0.01 ;{ }^{* * *} P<0.001\right)$. (B) Cell invasion in both BIRC5 knockout and control SKOV3 or OVCAR3 cells was examined using Matrigel-coated plates, and invaded cells were stained with H.E. and counted $\left({ }^{*} P<0.05 ;{ }^{* * *} P<0.001\right)$. 
A

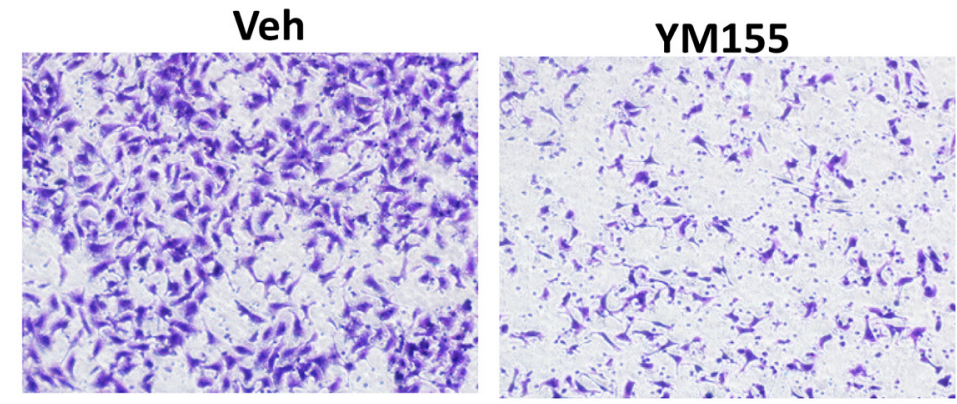

\section{SKOV3}
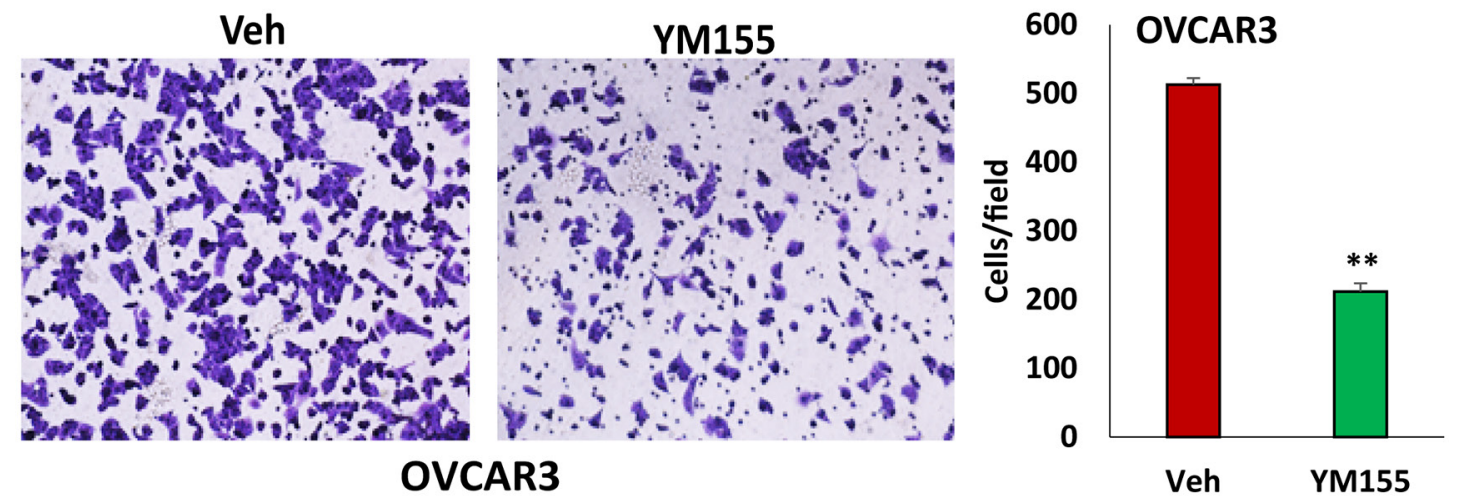

B

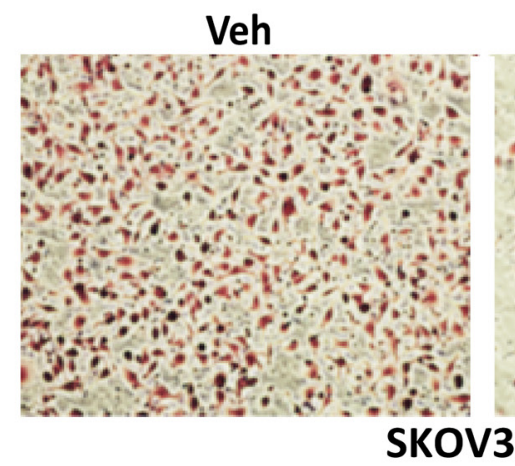

YM155
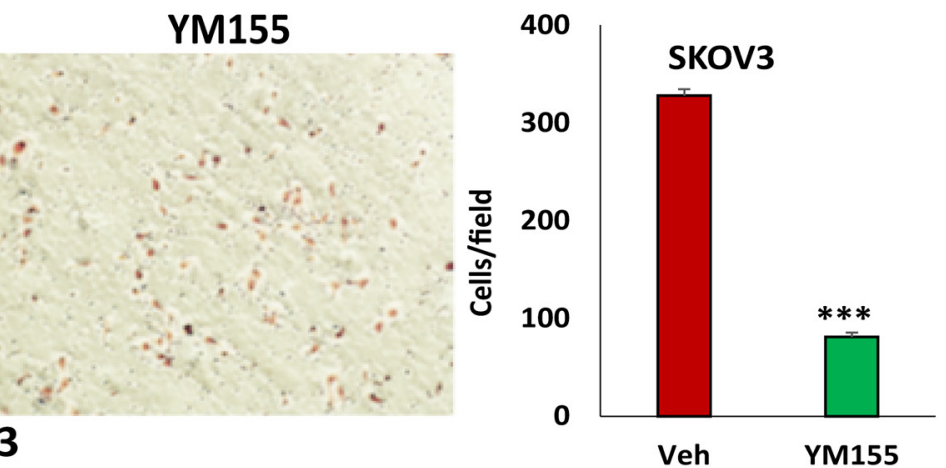

Veh

YM155

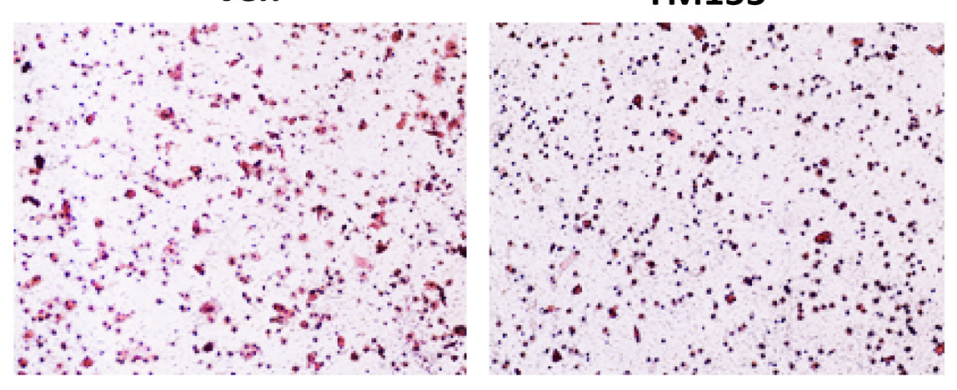

OVCAR3

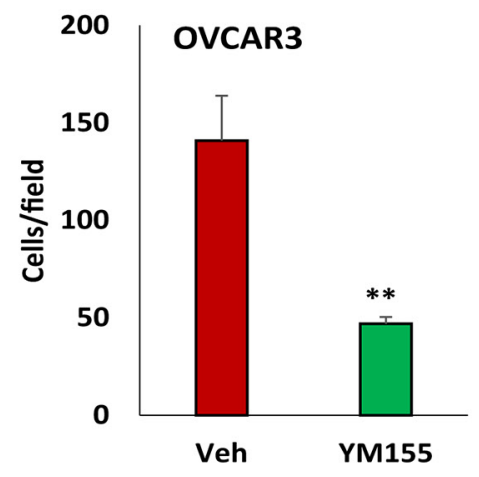

Figure 6: Inhibition of BIRC5 expression using YM155 reduced cell migration and invasion in ovarian cancer cells. (A) Cell migration in $5 \mathrm{nM}$ YM155- and vehicle-treated SKOV3 and OVCAR3 cells was examined using transwell plates, and migrated cells were stained with crystal blue and counted ${ }^{{ }^{* *}} P<0.01{ }^{* * *} P<0.001$ ). (B) SKOV3 and OVCAR3 cells were treated with 5 nM YM1 55 for $4 \mathrm{~h}$, and invasion was examined using Matrigel-coated plates, and invaded cells were stained with H.E. and counted $\left({ }^{*} P<0.05{ }^{* * *} P<0.001\right)$. 
blot. Loss of survivin resulted in attenuating the TGF $\beta$ signaling pathway in the BIRC5 knockout compared to control cells (Figure 8B). We also determined the TGF $\beta$ pathway following $20 \mathrm{nM}$ YM155 treatment and found that inhibition of survivin attenuated phospho-SMAD2 in both SKOV3 and OVCAR3 cells (Figure 8C). Our data indicated that loss of BIRC5 expression attenuated the TGF $\beta$ signaling pathway, thereby potentially leading to the inhibition of EMT in ovarian cancer cells.

\section{DISCUSSION}

BIRC5 is an effective drug target for cancer therapy due to its high expression in tumors, but not in normal tissues. BIRC5 was highly expressed in high grade serous ovarian carcinoma compared with ovarian, fallopian tube epithelia, and peritoneal fluid based on a large number of cancer patients from three different databases and current study. Furthermore, BIRC5 overexpression results in EMT alteration and tumor aggressive growth. Thus, targeting BIRC5 by using small molecule inhibitors like YM155 may provide a novel therapeutic approach in ovarian cancer therapy by inhibiting ovarian tumor metastasis and overcoming chemoresistance. BIRC5 expression significantly correlated with overall poor survival in patients based on analyzing data from 514 ovarian carcinomas. The results from our current study are consistent with findings from several previous studies showing that survivin is associated with poor survival and prognosis [31-34]. Although we showed that BIRC5 was highly expressed in high grade serous ovarian carcinoma, the role of BIRC5 expression in other types of ovarian cancer, including mucinous, clear cell, and endometrioid carcinoma was still unknown. Therefore, additional studies are required to determine the correlation of BIRC5 expression with diverse types of ovarian cancer at various
A

B

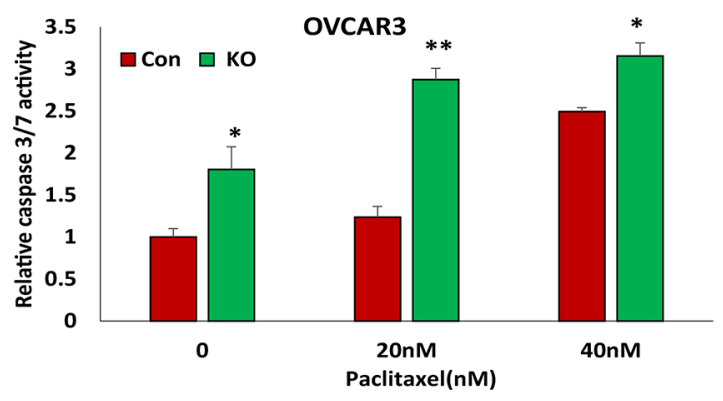

C

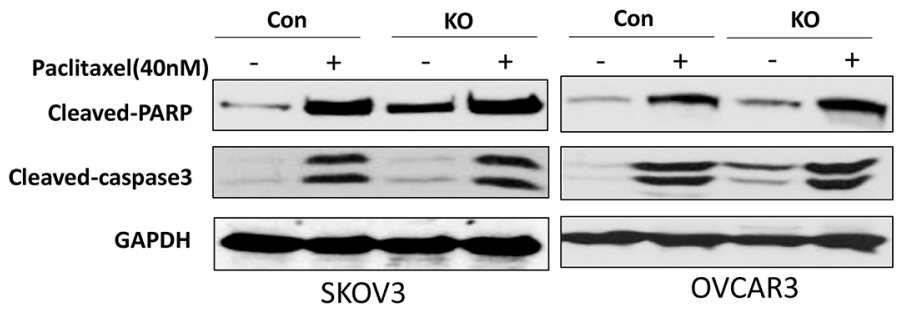

D

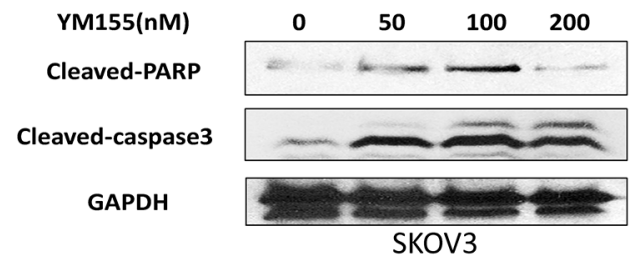

YM155(nM)

Cleaved-PARP

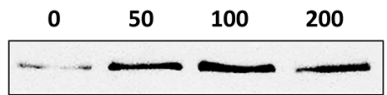

Cleaved-caspase 3

GAPDH

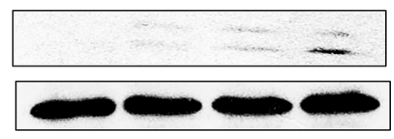

OVCAR3

Figure 7: Lentiviral CRISPR/Cas9 nickase-mediated BIRC5 gene editing sensitized cell responses to chemotherapy drug treatment. (A, B) Cell apoptosis in BIRC5 knockout and control SKOV3 (A) and OVCAR3 (B) cells following 20 and $40 \mathrm{nM}$ paclitaxel treatment for $24 \mathrm{~h}$ was determined by measuring caspase $3 / 7$ activity $\left({ }^{*} P<0.05 ;{ }^{* *} P<0.01\right)$. (C) Cell apoptosis in BIRC5 knockout and control SKOV3 and OVCAR3 cells following $40 \mathrm{nM}$ paclitaxel treatment for $24 \mathrm{~h}$ was examined by determining cleaved PARP and caspase3 using Western blot. (D) SKOV3 and OVCAR3 cell apoptosis was examined following treatment using different doses of YM155 by Western blot. 
disease stages in order to define its potential role in diagnosis, prognosis, and therapy.

Ovarian cancer therapy is limited due to its peritoneal spread behavior and chemoresistance. Understanding the underlying molecular mechanism will help find an effective approach by targeting at this process. In this study, we demonstrated for the first time that BIRC5 expression promoted EMT in ovarian cancer cells, which is consistent with a previous study reported in colorectal cancer [35]. However, it was also reported by another group that survivin inhibited EMT in hepatocellular carcinoma (HCC) [36]. EMT acquisition confers aggressive cellular behavior, which contributes to tumor metastasis and chemoresistance. Therefore, BIRC5 is a promising drug target for ovarian cancer therapy because of its role in EMT and undetectable expression in normal ovarian tissues. We have tested the function of survivin in ovarian cancer cells by disrupting BIRC5 with lentiviral CRISPR/Cas9 nickase mediated gene editing and a small molecule inhibitor, YM155. Disruption of BIRC5 expression by using both approaches resulted in reduced cell proliferation, migration, invasion, and colony formation in both SKOV3 and OVCAR3 cells. However, those functional assays showed that SKOV3 cells were more invasive than OVCAR3 cells, which may also be contributed by higher expression of survivin

A


B
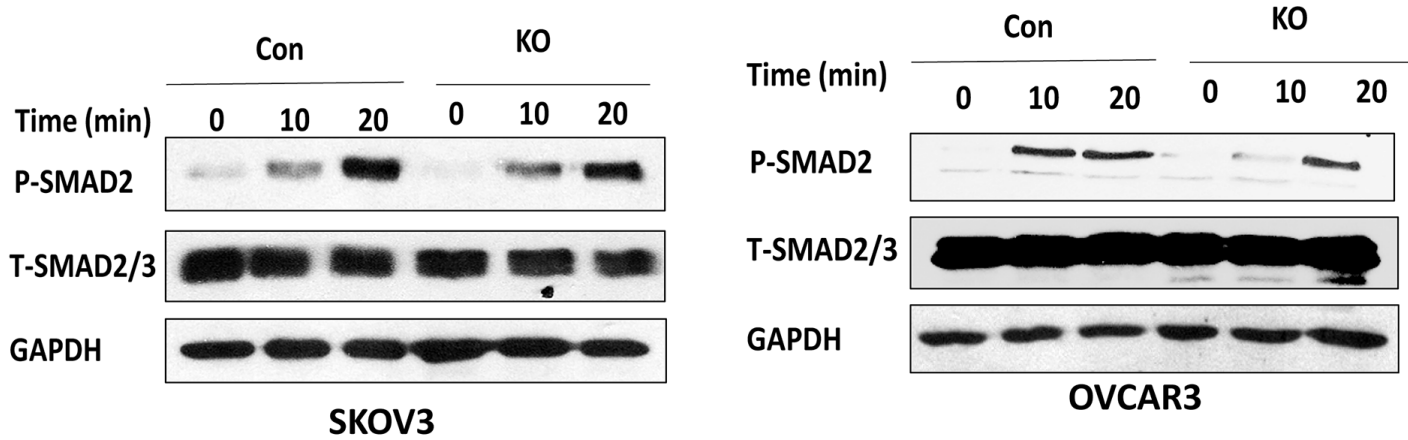

C
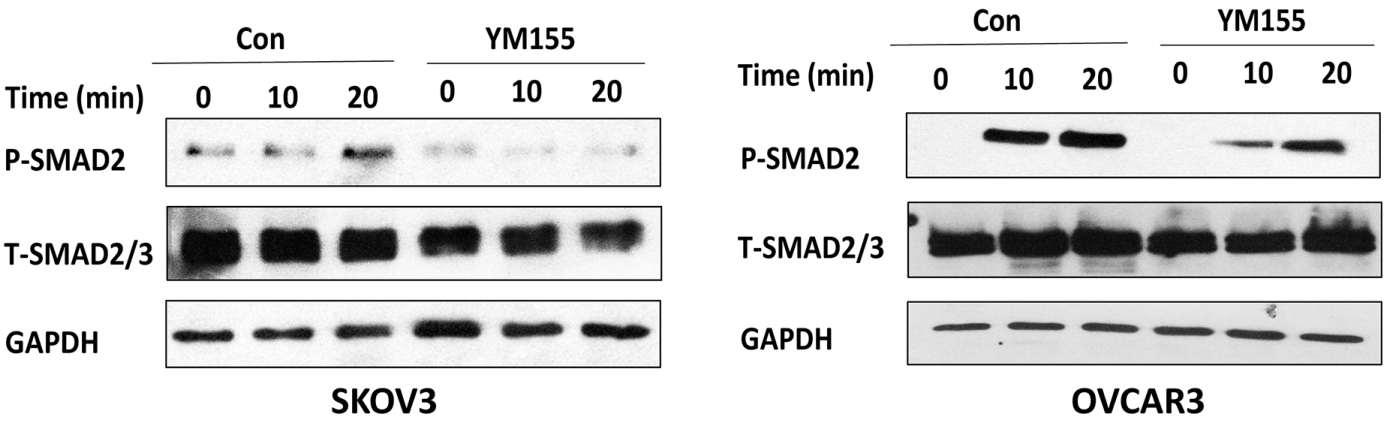

Figure 8: Lentiviral CRISPR/Cas9 nickase-mediated BIRC5 gene editing attenuated the TGF $\beta$ pathway in ovarian cancer cells. (A) TGF $\beta$ induced survivin in SKOV3 and OVCAR3 cells at the indicated time points as detected by Western blot. (B) The expression of phospho- and total SMAD2 in BIRC5 knockout and control SKOV3 and OVCAR3 cells was detected by Western blot following $10 \mathrm{ng} / \mathrm{ml}$ TGF $\beta$ treatment at the indicated time points. (C) The expression of phospho- and total SMAD2 was detected by Western blot in SKOV3 and OVCAR3 cells following $20 \mathrm{nM}$ YM155 treatment for $24 \mathrm{~h}$ and then treated with $10 \mathrm{ng} / \mathrm{ml} \mathrm{TGF} \beta$ at the indicated time points. 
in SKOV3 than OVCAR3 cells (Supplementary Figure 1). In addition, inhibition of survivin sensitized cell responses to chemotherapy drug treatment, indicating that BIRC5 is a therapeutic target for ovarian cancer therapy. Although no studies have so far reported on survivin and tumor metastasis in orthotopic ovarian cancer animal models, several studies have shown that silencing BIRC5 expression with siRNA, shRNA, or YM155 inhibited cell proliferation and sensitized the cell response to chemotherapy [22, 37-40]. Our data indicate that BIRC5 expression is potentially associated with ovarian tumor metastasis by promoting EMT. We are in the process of testing our hypothesis: inhibiting BIRC5 expression suppresses tumor metastasis in an orthotopic ovarian cancer mouse model by using selective small molecule survivin inhibitors.

Although we showed that the loss of BRIC5 expression led to an inhibition of EMT, the molecular mechanisms by which BIRC5 expression contributes to EMT is still largely unknown. It is well known that TGF $\beta$ promotes EMT in a variety of cancers, including ovarian cancer. For the first time, we found that BIRC5 expression was required for activating the TGF $\beta$ pathway and inhibiting survivin by using molecular or pharmacological approaches led to attenuating TGF $\beta$ signaling in ovarian cancer cells. Our data suggest that survivin promoted EMT by participating in the TGF $\beta$ pathway in ovarian cancer, which is consistent with a report in glioblastoma [41]. Previous studies showed that survivin is regulated by TGF $\beta$ through the ERK1/2 or PI3/AKT pathways in other cancer types including glioblastoma [41]. ERK1/2 is a positive regulator of EMT in numerous human cancers, including ovarian cancer $[42,43]$. However, survivin is downregulated by TGF $\beta$ in prostate cancer by downregulating downstream SMAD2/3, thereby inducing cell apoptosis [44], suggesting that TGF $\beta$ regulated survivin expression depends on cellular context. Therefore, it is possible that survivin-mediated EMT may occur through the TGF $\beta$, ERK1/2, and PI3/AKT pathways in ovarian cancer cells. In this study, we revealed that TGF $\beta$ activated survivin expression, and that loss of survivin attenuated TGF $\beta$ pathway, suggesting a positive feedback loop or crosstalk between survivin and TGF $\beta$ pathway, although it is not clear how survivin is involved in TGF $\beta$ pathway. In a previous study, XIAP (X-linked inhibitor of apoptosis protein), a member of the inhibitor of apoptosis family of proteins (IAP) was shown to directly interact with TGF $\beta$ receptor1 (TGF $\beta$ R1) through its baculovirus IAP repeat (BIR) domain [45]. Based on our data that showed the loss of survivin attenuated SMAD2, survivin may regulate TGF $\beta$ pathway through those components of upstream SMAD2, such as TGF $\beta$ R1. Therefore, it is possible that survivin as one of member IAP family may interact with TGF $\beta$ R 1 through its BIR domain, thus activate TGF $\beta$ pathway in ovarian cancer cells.
In conclusion, our study demonstrated that BIRC5 is highly expressed in ovarian cancer cells and associated with a patient's poor survival or prognosis. Disrupting BRIC5 expression by using the lentiviral CRISPR/Cas9 nickase vector or small molecule inhibitor, YM155, inhibited EMT and significantly reduced cell growth and invasion and induced cell apoptosis. Loss of BIRIC5 expression attenuated the TGF $\beta$ pathway. Therefore, BRIC5 may contribute to EMT by potentially participating in the TGF $\beta$ pathway in ovarian cancer cells.

\section{MATERIALS AND METHODS}

\section{Cell culture}

Ovarian cancer cell lines, SKOV3, OVCAR3, Hey and UACC1598 were obtained from ATCC and cultured in Dulbecco's Modified Eagle Medium (DMEM) supplemented with 10\% FBS (Hyclone; Logan, UT), 100 $\mathrm{U} / \mathrm{ml}$ penicillin, and $100 \mu \mathrm{g} / \mathrm{ml}$ streptomycin (Invitrogen; Carlsbad, CA). HEK293 FT cells were cultured in DMEM supplemented with $10 \% \mathrm{FBS}, 100 \mathrm{U} / \mathrm{ml}$ penicillin, $100 \mu \mathrm{g} /$ $\mathrm{ml}$ streptomycin, $1 \%$ glutamine, $1 \%$ nonessential amino acids, and geneticin at a final concentration of $1 \mu \mathrm{g} / \mathrm{ml}$.

\section{Lentiviral vector production}

The lentiviral CRISPR/Cas9 nickase-mediated BIRC5 gene editing vectors were constructed by annealing four gRNA oligonucleotide pairs and subcloning them in the BsmII site of lentiviral vector Lentiguide-puro vector (\#52963, Addgene), and gRNAs were driven by human U6 promoter. Two gRNA sequences, 5'CGGGTCCCGCGATTCAAATC and 5'AGAGGTGGCGGCGGCGGCAT, were designed. CRISPRcas9 nickase was in a separate vector, LentiCas9blast (\#52962, Addgene) and driven by EF1a promoter. Lentiviral BIRC5 overexpression vector was purchased from Applied Biological Materials Inc (Richmond, Canada). Lentivirus was produced by packaging in 293FT cells, as published previously [46]. Stable cell lines were generated by transducing the SKOV3 and OVCAR3 cells with the lentiviral CRISPR/Cas9 nickase-mediated BIRC5 gene editing and lentiCas9-blast Cas9 nickase vectors and selected with $5 \mu \mathrm{g} / \mathrm{ml}$ puromycin or $10 \mathrm{ug} / \mathrm{ml}$ blasticidin. LentiCas9-blast was used as the control vector without gRNAs.

\section{Surveyor mutation assay}

Genomic DNA was extracted from SKOV3 ovarian cancer cells transduced with lentiviral CRISPR/Cas9 nickase BIRC5 and control vectors. PCR was performed by amplifying the mutated region. The primer pairs used to detect BIRC5 mutations were 5'TGCCTAGGCCTCTCAAAGTG and 5'AAGACTTACATGGGGTCGTCA in surveyor 
mutation assay. PCR product was denatured and reannealed with the PCR program: $95^{\circ} \mathrm{C}$ denatured for $5 \mathrm{~min}$, ramped down to $85^{\circ} \mathrm{C}$ at $-2^{\circ} \mathrm{C} / \mathrm{s}$ and then ramped down to $25^{\circ} \mathrm{C}$ at $-0.1^{\circ} \mathrm{C} / \mathrm{s}$; held at $4^{\circ} \mathrm{C}$. Afterwards, 10 units of $\mathrm{T} 7$ endonuclease I was added and incubated at $37^{\circ} \mathrm{C}$ for $30 \mathrm{~min}$, and the reaction was stopped by adding $2 \mu \mathrm{l}$ of $0.25 \mathrm{M}$ EDTA and then visualized on a $1.2 \%$ agarose gel.

\section{MTT assay}

SKOV3 or OVCAR3 cells (8000/well) transduced with lentiviral CRISPR/Cas9 nickase for BIRC5 editing and control vectors were plated into 96-well plates and cultured at different time points $(24,48$ and $72 \mathrm{~h})$. Thereafter, $10 \mu \mathrm{l}$ of MTT reagent was added to each well and incubated for $\sim 4 \mathrm{~h}$ and then terminated by adding $100 \mu$ detergent reagent to incubate at $22^{\circ} \mathrm{C}$ in the dark for $2 \mathrm{~h}$. Cell proliferation was assessed by measuring the absorbance at $570 \mathrm{~nm}$ wavelength.

\section{Cell clonogenic survival assay}

400 BIRC5 knockout and control SKOV3 and OVCAR3 cells or wild type cells treated with YM155 or vehicle were seeded on 6-well plates and cultured for 2 weeks and then fixed with 70\% ethanol and stained with crystal blue. Colonies were counted for statistical analysis in triplicate.

\section{Cell migration assay}

The cell migration assay was performed using a modified transwell chamber (BD Falcon ${ }^{\mathrm{TM}}$, San Jose, CA). These chambers were inserted into 24-well cell culture plates. SKOV3 or OVCAR3 cells transduced with lentiviral BIRC5 Cas9 nickase gRNAs and control vectors $\left(3 \times 10^{4}\right)$ in $300 \mu \mathrm{l}$ serum-free DMEM were added to the upper chamber. DMEM containing 10\% FBS (serving as the chemoattractant) was added into the lower chamber of each well and incubated for $24 \mathrm{~h}$. The medium and nonmigrated cells in the upper chamber were removed, while the migrated cells on the lower side of the membranes were fixed with methanol and stained with crystal violet. Pictures were taken at $10 \mathrm{X}$ magnification, and cells from at least three different fields were counted.

\section{Cell invasion assay}

SKOV3 and OVCAR3 $\left(5 \times 10^{5}\right)$ cells transduced with lentiviral BIRC5 gRNA and control vectors were seeded in serum-free DMEM onto inserts precoated with Matrigel (BD BioCoat ${ }^{\mathrm{TM}}$ using 24-well Tumor Invasion System (BD BioSciences, San Jose, CA). DMEM containing 10\% FBS was added to the bottom chamber of the invasion system as the chemoattractant. The transwell inserts were stained for 5 min with hematoxylin and eosin following methanol fixation for $20 \mathrm{~min}$ following overnight incubation. Pictures were taken at $10 \mathrm{X}$ magnification. Invaded cells were counted in at least three different fields.

\section{Immunofluorescent staining}

To detect survivin gene expression, ovarian serous carcinoma sections were antigen-retrieved and incubated with blocking buffer (5\% normal goat serum, 3\% bovine serum albumin, and $0.1 \%$ Triton-X100 in PBS) for 1 $\mathrm{h}$. The slides were incubated overnight with primary antibodies to survivin (1:200 dilution, Cell Signaling, Danvers, MA). After rinsing three times for $5 \mathrm{~min}$ with PBST, Alexa 488- or 594- conjugated goat anti-rabbit (Invitrogen, Carlsbad, CA) antibodies were added for 1 $\mathrm{h}$ at room temperature. Cell nuclei were counterstained with DAPI (Vector Laboratories, Inc.; Burlingame, CA). Images were captured on a Zeiss LSM700 laser scanning confocal microscope.

\section{Tissue microarray and immunohistochemistry}

Tissue microarray (TMA) including 10 cases of high grade serous ovarian cancer tumors and 10 cases of normal fallopian tubes was prepared at Northwestern University Pathological Core Facility. TMA were sectioned at $4 \mu \mathrm{m}$ in thickness. TMA slides were deparaffinized in xylene and rehydrated in a graded series of ethanol. After antigen retrieval, all immunohistochemical staining was performed on a Ventana Nexus automated system. In brief, endogenous peroxidase activity was blocked with $3 \%$ hydrogen peroxide. After blocking in $1.5 \%$ normal goat serum for $30 \mathrm{~min}$ at room temperature, slides were then incubated overnight at $4{ }^{\circ} \mathrm{C}$ with rabbit polyclonal anti-survivin $(1: 250)$ in a humid chamber. Staining was detected with I-View 3, 3'-diaminobenzidine (DAB) detection system. Semi-quantitative immunointensity was scored in carcinoma tumor cells and normal fallopian epithelial cells as 0 (negative), 1 (weak), 2 (moderate) and 3 (strong) and percentage was showed as $\%$.

\section{Cell apoptosis}

Stable SKOV3 and OVCAR3 cancer cell lines established with lentiviral BRIC5 gRNA and control vectors were treated with the chemotherapy drug paclitaxel at different doses $(0,20,40 \mathrm{nM})$ for $24 \mathrm{~h}$. Apoptosis was measured using a caspase $3 / 7$ activity assay kit (Promega, Madison, WI). Cell apoptosis was also detected in both SKOV3 and OVCAR3 cells transduced with lentiviral CRISPR/Cas9 nickase-mediated BIRC5 gRNAs and control vectors by using Western blot by detecting cleaved PARP and active caspase 3 .

\section{Western blot}

Ovarian cancer cells were collected in RIPA buffer (Thermo Scientific; Rockford, IL) containing 1\% 
Halt Proteinase Inhibitor Cocktail (Thermo Scientific; Rockford, IL). An equal amount of protein (40 $\mu \mathrm{g} /$ lane) was loaded onto $10 \%$ SDS-PAGE gels and transferred onto nitrocellulose membranes. The membranes were blocked with $5 \%$ nonfat milk for $1 \mathrm{~h}$ and incubated with primary antibodies against PDCD4 (Cell Signaling), GAPDH (Sigma; St. Louis, MO), vimentin, E-cadherin, or snail2 (Cell Signaling), cytokeratin-7.

\section{Statistical analysis}

Significant differences were determined from at least two independent experiments performed in triplicate and presented as means \pm SD by using Student's $t$-test. $P$ $<0.05$ was considered significant.

\section{ACKNOWLEDGMENTS AND FUNDING}

This study was partially supported by a grant from AHA (JY) and West Cancer Center (JY) and NIH grant R01CA193609-01A1 (WL). W. Qiang was partially supported by NU-PSOC (U54 CA193419) and Robert H. Lurie Comprehensive Cancer Center OncoSET initiatives at the Northwestern University. The content is solely the responsibility of the authors and does not necessarily represent the official views of the NIH.

\section{CONFLICTS OF INTEREST}

The authors declare no conflicts of interest.

\section{REFERENCES}

1. Siegel RL, Miller KD, Jemal A. Cancer Statistics, 2017. CA Cancer J Clin. 2017; 67:7-30.

2. Scalici JM, Arapovic S, Saks EJ, Atkins KA, Petroni G, Duska LR, Slack-Davis JK. Mesothelium expression of vascular cell adhesion molecule-1 (VCAM-1) is associated with an unfavorable prognosis in epithelial ovarian cancer (EOC). Cancer. 2017; 123:977-984.

3. Ahmed N, Stenvers KL. Getting to know ovarian cancer ascites: opportunities for targeted therapy-based translational research. Front Oncol. 2013; 3:256.

4. Nagai T, Oshiro H, Sagawa Y, Sakamaki K, Terauchi F, Nagao T. Pathological Characterization of Ovarian Cancer Patients Who Underwent Debulking Surgery in Combination With Diaphragmatic Surgery: A CrossSectional Study. Medicine (Baltimore). 2015; 94:e2296.

5. Vergara D, Merlot B, Lucot JP, Collinet P, Vinatier D, Fournier I, Salzet M. Epithelial-mesenchymal transition in ovarian cancer. Cancer Lett. 2010; 291:59-66.

6. Yoshida S, Furukawa N, Haruta S, Tanase Y, Kanayama S, Noguchi T, Sakata M, Yamada Y, Oi H, Kobayashi H. Expression profiles of genes involved in poor prognosis of epithelial ovarian carcinoma: a review. Int J Gynecol Cancer. 2009; 19:992-997.

7. Arend RC, Londono-Joshi AI, Straughn JM Jr, Buchsbaum DJ. The Wnt/beta-catenin pathway in ovarian cancer: a review. Gynecol Oncol. 2013; 131:772-779.

8. Chou JL, Chen LY, Lai HC, Chan MW. TGF-beta: friend or foe? The role of TGF-beta/SMAD signaling in epigenetic silencing of ovarian cancer and its implication in epigenetic therapy. Expert Opin Ther Targets. 2010; 14:1213-1223.

9. Wu J, Liu Z, Shao C, Gong Y, Hernando E, Lee P, Narita M, Muller W, Liu J, Wei JJ. HMGA2 overexpression-induced ovarian surface epithelial transformation is mediated through regulation of EMT genes. Cancer Res. 2011; 71:349-359.

10. Zhou XM, Zhang H, Han X. Role of epithelial to mesenchymal transition proteins in gynecological cancers: pathological and therapeutic perspectives. Tumour Biol. 2014; 35:9523-9530.

11. Deng J, Wang L, Chen H, Hao J, Ni J, Chang L, Duan W, Graham P, Li Y. Targeting epithelial-mesenchymal transition and cancer stem cells for chemoresistant ovarian cancer. Oncotarget. 2016; 7:55771-55788. https://doi. org/10.18632/oncotarget.9908.

12. Ahmed N, Abubaker K, Findlay J, Quinn M. Epithelial mesenchymal transition and cancer stem cell-like phenotypes facilitate chemoresistance in recurrent ovarian cancer. Curr Cancer Drug Targets. 2010; 10:268-278.

13. Amankwah EK, Lin HY, Tyrer JP, Lawrenson K, Dennis J, Chornokur G, Aben KK, Anton-Culver H, Antonenkova N, Bruinsma F, Bandera EV, Bean YT, Beckmann MW, et al. Epithelial-Mesenchymal Transition (EMT) Gene Variants and Epithelial Ovarian Cancer (EOC) Risk. Genet Epidemiol. 2015; 39:689-697.

14. Helleman J, Smid M, Jansen MP, van der Burg ME, Berns EM. Pathway analysis of gene lists associated with platinum-based chemotherapy resistance in ovarian cancer: the big picture. Gynecol Oncol. 2010; 117:170-176.

15. Takai M, Terai Y, Kawaguchi H, Ashihara K, Fujiwara S, Tanaka T, Tsunetoh S, Tanaka Y, Sasaki H, Kanemura M, Tanabe A, Ohmichi M. The EMT (epithelial-mesenchymaltransition)-related protein expression indicates the metastatic status and prognosis in patients with ovarian cancer. J Ovarian Res. 2014; 7:76.

16. Liguang Z, Peishu L, Hongluan M, Hong J, Rong W, Wachtel MS, Frezza EE. Survivin expression in ovarian cancer. Exp Oncol. 2007; 29:121-125.

17. Chen L, Liang L, Yan X, Liu N, Gong L, Pan S, Lin F, Zhang Q, Zhao H, Zheng F. Survivin status affects prognosis and chemosensitivity in epithelial ovarian cancer. Int J Gynecol Cancer. 2013; 23:256-263.

18. Parvani JG, Davuluri G, Wendt MK, Espinosa C, Tian M, Danielpour D, Sossey-Alaoui K, Schiemann WP. Deptor enhances triple-negative breast cancer metastasis and 
chemoresistance through coupling to survivin expression. Neoplasia. 2015; 17:317-328.

19. Nestal de Moraes G, Delbue D, Silva KL, Robaina MC, Khongkow P, Gomes AR, Zona S, Crocamo S, Mencalha AL, Magalhaes LM, Lam EW, Maia RC. FOXM1 targets XIAP and Survivin to modulate breast cancer survival and chemoresistance. Cell Signal. 2015; 27:2496-2505.

20. Czyz M, Lesiak-Mieczkowska K, Koprowska K, Szulawska-Mroczek A, Wozniak M. Cell context-dependent activities of parthenolide in primary and metastatic melanoma cells. Br J Pharmacol. 2010; 160:1144-1157.

21. Zhou L, Liu P, Chen B, Wang Y, Wang X, Chiriva Internati M, Wachtel MS, Frezza EE. Silibinin restores paclitaxel sensitivity to paclitaxel-resistant human ovarian carcinoma cells. Anticancer Res. 2008; 28:1119-1127.

22. Jiang L, Luo RY, Yang J, Cheng YX. Knockdown of survivin contributes to antitumor activity in cisplatinresistant ovarian cancer cells. Mol Med Rep. 2013; 7:425-430.

23. Lili LN, Matyunina LV, Walker LD, Wells SL, Benigno $\mathrm{BB}$, McDonald JF. Molecular profiling supports the role of epithelial-to-mesenchymal transition (EMT) in ovarian cancer metastasis. J Ovarian Res. 2013; 6:49.

24. Yan H, Sun Y. Evaluation of the mechanism of epithelialmesenchymal transition in human ovarian cancer stem cells transfected with a WW domain-containing oxidoreductase gene. Oncol Lett. 2014; 8:426-430.

25. Kandoth C, McLellan MD, Vandin F, Ye K, Niu B, Lu C, Xie M, Zhang Q, McMichael JF, Wyczalkowski MA, Leiserson MDM, Miller CA, Welch JS, et al. Mutational landscape and significance across 12 major cancer types. Nature. 2013; 502:333-339.

26. Bonome T, Levine DA, Shih J, Randonovich M, PiseMasison CA, Bogomolniy F, Ozbun L, Brady J, Barrett JC, Boyd J, Birrer MJ. A gene signature predicting for survival in suboptimally debulked patients with ovarian cancer. Cancer Res. 2008; 68:5478-5486.

27. Yoshihara K, Tajima A, Komata D, Yamamoto T, Kodama S, Fujiwara H, Suzuki M, Onishi Y, Hatae M, Sueyoshi K, Fujiwara H, Kudo Y, Inoue I, Tanaka K. Gene expression profiling of advanced-stage serous ovarian cancers distinguishes novel subclasses and implicates ZEB2 in tumor progression and prognosis. Cancer Sci. 2009 100:1421-1428.

28. Goswami CP, Nakshatri H. PROGgene: gene expression based survival analysis web application for multiple cancers. J Clin Bioinforma. 2013; 3:22

29. Kobayashi M, Salomon C, Tapia J, Illanes SE, Mitchell $\mathrm{MD}$, Rice GE. Ovarian cancer cell invasiveness is associated with discordant exosomal sequestration of Let-7 miRNA and miR-200. J Transl Med. 2014; 12:4.

30. Chen Z, Wang Y, Liu W, Zhao G, Lee S, Balogh A, Zou Y, Guo Y, Zhang Z, Gu W, Li C, Tigyi G, Yue J. Doxycycline inducible Kruppel-like factor 4 lentiviral vector mediates mesenchymal to epithelial transition in ovarian cancer cells. PLoS One. 2014; 9:e105331.

31. Dobrzycka B, Mackowiak-Matejczyk B, Terlikowska KM, Kulesza-Bronczyk B, Kinalski M, Terlikowski SJ. Prognostic significance of pretreatment VEGF, survivin, and Smac/DIABLO serum levels in patients with serous ovarian carcinoma. Tumour Biol. 2015; 36:4157-4165.

32. Gasowska-Bodnar A, Bodnar L, Dabek A, Cichowicz M, Jerzak M, Cierniak S, Kozlowski W, Baranowski W. Survivin expression as a prognostic factor in patients with epithelial ovarian cancer or primary peritoneal cancer treated with neoadjuvant chemotherapy. Int J Gynecol Cancer. 2014; 24:687-696.

33. No JH, Jeon YT, Kim YB, Song YS. Quantitative detection of serum survivin and its relationship with prognostic factors in ovarian cancer. Gynecol Obstet Invest. 2011; $71: 136-140$

34. Athanassiadou P, Grapsa D, Athanassiades P, Gonidi M, Athanassiadou AM, Tsipis A, Patsouris E. The prognostic significance of COX-2 and survivin expression in ovarian cancer. Pathol Res Pract. 2008; 204:241-249.

35. Lee SC, Kim OH, Lee SK, Kim SJ. IWR-1 inhibits epithelial-mesenchymal transition of colorectal cancer cells through suppressing Wnt/ $\beta$-catenin signaling as well as survivin expression. Oncotarget. 2015; 6:27146-27159. https://doi.org/10.18632/oncotarget.4354.

36. Tai CJ, Chin-Sheng H, Kuo LJ, Wei PL, Lu HH, Chen HA, Liu TZ, Liu JJ, Liu DZ, Ho YS, Wu CH, Chang YJ. Survivin-mediated cancer cell migration through GRP78 and epithelial-mesenchymal transition (EMT) marker expression in Mahlavu cells. Ann Surg Oncol. 2012; 19:336-343

37. Ma X, Wang S, Zhou J, Xing H, Xu G, Wang B, Chen G, $\mathrm{Lu}$ YP, Ma D. Induction of apoptosis in human ovarian epithelial cancer cells by antisurvivin oligonucleotides. Oncol Rep. 2005; 14:275-279.

38. Azrak RG, Frank CL, Ghadersohi A, Rustum YM. Silencing survivin results in synergy between methylseleninic acid and paclitaxel against skov3 ovarian cancer cells. Cancer Biol Ther. 2008; 7:1901-1908.

39. Wang J, Zheng Y, Yang F, Zhao P, Li H. Survivin small interfering RNA transfected with a microbubble and ultrasound exposure inducing apoptosis in ovarian carcinoma cells. Int J Gynecol Cancer. 2010; 20:500-506.

40. Mir R, Stanzani E, Martinez-Soler F, Villanueva A, Vidal A, Condom E, Ponce J, Gil J, Tortosa A, Gimenez-Bonafe P. YM155 sensitizes ovarian cancer cells to cisplatin inducing apoptosis and tumor regression. Gynecol Oncol. 2014; 132:211-220.

41. Chen W, Zhong X, Wei Y, Liu Y, Yi Q, Zhang G, He L, Chen F, Liu Y, Luo J. TGF-beta Regulates Survivin to Affect Cell Cycle and the Expression of EGFR and MMP9 in Glioblastoma. Mol Neurobiol. 2016; 53:1648-1653. 
42. Xie L, Law BK, Chytil AM, Brown KA, Aakre ME, Moses HL. Activation of the Erk pathway is required for TGFbeta1-induced EMT in vitro. Neoplasia. 2004; 6:603-610.

43. Strippoli R, Loureiro J, Moreno V, Benedicto I, Perez Lozano ML, Barreiro O, Pellinen T, Minguet S, Foronda M, Osteso MT, Calvo E, Vázquez J, López Cabrera M, del Pozo MA. Caveolin-1 deficiency induces a MEK-ERK1/2Snail-1-dependent epithelial-mesenchymal transition and fibrosis during peritoneal dialysis. EMBO Mol Med. 2015; 7:102-123.

44. Yang J, Song K, Krebs TL, Jackson MW, Danielpour D. $\mathrm{Rb} / \mathrm{E} 2 \mathrm{~F} 4$ and Smad2/3 link survivin to TGF-beta-induced apoptosis and tumor progression. Oncogene. 2008; 27:5326-5338.

45. Neil JR, Tian M, Schiemann WP. X-linked inhibitor of apoptosis protein and its E3 ligase activity promote transforming growth factor-\{beta $\}$-mediated nuclear factor\{kappa\}B activation during breast cancer progression. J Biol Chem. 2009; 284:21209-21217.

46. Yue J, Sheng Y, Ren A, Penmatsa S. A miR-21 hairpin structure-based gene knockdown vector. Biochem Biophys Res Commun. 2010; 394:667-672. 